\title{
BMJ Open Systematic review and meta-analysis of the prognosis and prognostic factors of interstitial pneumonia with autoimmune features
}

\author{
Hiroyuki Kamiya (D) , ${ }^{1}$ Ogee Mer Panlaqui ${ }^{2}$
}

To cite: Kamiya H, Panlaqui OM. Systematic review and metaanalysis of the prognosis and prognostic factors of interstitial pneumonia with autoimmune features. BMJ Open 2019;9:e031444. doi:10.1136/ bmjopen-2019-031444

- Prepublication history and additional material for this paper are available online. To view these files, please visit the journal online (http://dx.doi. org/10.1136/bmjopen-2019031444).

Received 04 May 2019 Revised 22 0ctober 2019 Accepted 22 October 2019
Check for updates

(C) Author(s) (or their employer(s)) 2019. Re-use permitted under CC BY-NC. No commercial re-use. See rights and permissions. Published by BMJ.

${ }^{1}$ School of Population and Global Health, University of Western Australia, Crawley, Western Australia, Australia

${ }^{2}$ Department of Intensive Care Medicine, Northern Hospital, Epping, Victoria, Australia

Correspondence to Dr Hiroyuki Kamiya; mlb04194@nifty.com

\section{ABSTRACT}

Objective To clarify the prognosis and prognostic factors of interstitial pneumonia with autoimmune features (IPAF) in comparison to idiopathic pulmonary fibrosis (IPF), the most common idiopathic interstitial pneumonia, and connective tissue disease-associated interstitial pneumonia (CTD-IP).

Design A systematic review and meta-analysis.

Data sources Electronic databases such as Medline and Embase were searched from 2015 through 6 September 2019.

Eligibility criteria for selecting studies Primary studies that comparatively investigated the prognosis or prognostic factors of IPAF were eligible.

Data extraction and analysis Two reviewers extracted relevant data and assessed the risk of bias independently. A meta-analysis was conducted using a random-effects model. The quality of presented evidence was assessed by the Grades of Recommendation, Assessment, Development, and Evaluation system.

Results Out of a total of 656 records retrieved, 12 studies were reviewed. The clinical features of IPAF were diverse between studies, which included a radiological and/or pathological usual interstitial pneumonia (UIP) pattern of between $0 \%$ and $73.8 \%$. All studies contained some risk of bias. There was no significant difference of all-cause mortality between IPAF-UIP and IPF in all studies, although the prognosis of IPAF in contrast to IPF or CTD-IP varied between studies depending on the proportion of UIP pattern. Among the potential prognostic factors identified, age was significantly associated with all-cause mortality of IPAF by a pooled analysis of univariate results with a hazard ratio (HR) of 1.06 (95\% confidence interval (Cl) 1.04 to 1.07). The adjusted effect of age was also significant in all studies. The quality of presented evidence was deemed as very low.

Conclusion There was no significant difference of all-cause mortality between IPAF-UIP and IPF. Age was deemed as a prognostic factor for all-cause mortality of IPAF. The findings should be interpreted cautiously due to the low quality of the presented evidence.

PROSPERO registration number CRD42018115870.

\section{INTRODUCTION}

Interstitial pneumonia (IP) is a heterogeneous clinical entity that is pathologically
Strengths and limitations of this study

- This study was a systematic review based on a comprehensive literature search to accumulate all of the evidence that is currently available.

- The results were statistically synthesised to overcome the shortcoming of a small study, which is usually the case with reports of interstitial pneumonia with autoimmune features.

- Most of the findings were inconclusive due to a small number of studies and the scarcity of multivariate analyses.

characterised by varying degrees of a mixture of inflammation and fibrosis in the interstitium of pulmonary parenchyma. ${ }^{1}$ Although its pathogenesis is yet to be confirmed, IP is known to be accompanied by other medical conditions such as connective tissue disease (CTD), occupational dust exposure and drug toxicity. ${ }^{2-4}$ It is essential to identify these known causes and discriminate between idiopathic IPs (IIPs) and secondary IPs, because therapeutic strategies and prognosis for these diseases are different. ${ }^{5}$ Among these known aetiologies, CTDs are the most common underlying disease and are reported to be associated with approximately $30 \%$ of cases of IP that were initially diagnosed as IIPs. ${ }^{6}$ However, it is often difficult to make a definitive diagnosis of CTD-associated IP (CTD-IP) because IP can be a sole presenting manifestation of certain CTDs, ${ }^{7}$ or the symptoms and signs suggestive of CTDs may be too subtle to be recognised as an underlying disease. ${ }^{8}$ Furthermore, some cases remain undiagnosed as a defined CTD under current classification criteria regardless of the implication of autoimmune features. ${ }^{9}$ This latter case has been a subject of debate over the last decade because clinical differences between undifferentiated CTD-IP (UCTD-IP) and defined CTD-IP or IIP are closely related to 
the management of patients with IP. ${ }^{10}$ However, different research groups have implemented different nomenclatures with diverse classification criteria to investigate this medical condition, and thus previous literature is flooded with inconsistent results derived from heterogeneous groups of patients who were recruited based on the same concept of the disease. ${ }^{1-14}$ In order to address these chaotic circumstances and facilitate a prospective study targeting a uniform cohort of patients who can be classified into a possibly new clinical entity, the European Respiratory Society (ERS) and the American Thoracic Society (ATS) Task Force proposed the new term 'interstitial pneumonia with autoimmune features (IPAF)' and reported its classification criteria in $2015 .{ }^{15}$ The criteria of IPAF are composed of clinical, serological and morphological domains (multiple features constituting each domain), and at least one feature from at least two of the domains each is required to be positive for the diagnosis of IPAF after confirming the presence of IP and excluding alternative aetiologies for the disease. ${ }^{15}$ Since the introduction of this terminology, many researchers have started using these classification criteria to describe patients with IP suggestive of autoimmune features who cannot be diagnosed as a defined CTD. ${ }^{16}$ Although the attempt of the Task Force was successful in this regard, the findings of recent reports remain diverse, and it is still unclear whether IPAF is a unique clinical entity from CTD-IP or IIP, in particular, idiopathic pulmonary fibrosis (IPF), which is the most common type of IIP. ${ }^{17}$ Therefore, the aim of this systematic review was to summarise previous reports of IPAF and present current evidence focusing on the prognosis and prognostic factors of IPAF in comparison to CTD-IP or IIPs.

\section{METHODS}

This review was conducted and reported according to the Preferred Reporting Items for Systematic Reviews and Meta-Analyses (PRISMA) ${ }^{18}$ and the Meta-analysis of Observational Studies in Epidemiology (MOOSE) statement. $^{19}$

\section{Patient and public involvement}

There was no patient or public involvement in the whole process of conducting this research.

\section{Eligibility}

This review included any type of primary study that compared the prognosis of IPAF with that of CTD-IP or IIPs such as IPF and idiopathic non-specific interstitial pneumonia, except for a case report. The studies that investigated the prognostic factors of IPAF for predefined outcomes were also eligible. IPAF was diagnosed based on the classification criteria proposed by the ERS/ATS Task Force in 2015, which consisted of CTD-specific features categorised into clinical, serological and morphological domains. ${ }^{15}$ IIPs were diagnosed based on the ATS/ERS statement, ${ }^{1}$ and a defined CTD was diagnosed based on its widely accepted classification criteria including the American College of Rheumatology criteria for rheumatoid arthritis. ${ }^{20-25}$ Although various terminologies had previously been implemented to describe patients who would have been classified as IPAF, ${ }^{11-14}$ they were excluded due to concerns about recruiting a potentially heterogeneous group of people regardless of their overlapping clinical features. ${ }^{26}$ There was no limitation on follow-up period, and patients were included at any point of time during their disease course.

Potential prognostic factors were designated in this study and defined as any clinical information related to predefined outcomes such as demographic features, pulmonary functions, laboratory data and radiological and/or pathological patterns of IP.

Primary outcomes were all-cause and pulmonary-cause mortality. Secondary outcomes were a progression of the disease and deterioration of health-related quality of life. The progression of the disease was defined by each research group based on a combination of symptomatic, functional and/or radiological deterioration. The development of a defined CTD over the follow-up periods was also included as a secondary outcome.

Only English articles published in 2015 or later were eligible because the IPAF criteria were presented at the ERS congress and published in the European Respiratory Journal in that year. ${ }^{15}$ Editorials, letters and review articles were all ineligible, and conference proceedings were also excluded due to concerns about insufficient information.

\section{Search of studies}

Electronic databases, Medline (Ovid), Embase (Ovid) and Science Citation Index Expanded (Web of Science) were searched from 2015 through 24 December 2018. The search was updated on 6 September 2019. Because there had been no established subject heading for IPAF, other relevant terms such as 'interstitial lung disease' and 'undifferentiated connective tissue disease' were used and combined with text words of the study population to construct a string of search terms (eg, ('interstitial lung disease' or 'interstitial pneumonia' or 'pulmonary fibrosis') AND ('undifferentiated connective tissue disease' or 'interstitial pneumonia with autoimmune features')). Methodology filters such as 'prognosis' were not used to increase the sensitivity of the search (online supplemenatry e-Appendix). Grey literature was sought through Google Scholar. ${ }^{27}$ Reference lists of eligible studies and relevant review articles were hand searched, and cross referencing was also used to identify additional reports.

\section{Study selection and data collection}

Two reviewers (HK and OMP) independently examined the titles and abstracts of all retrieved articles after removing duplicates and selected eligible studies. Data were also extracted by the same reviewers based on a data extraction form, which was adopted and modified from a previously published article. ${ }^{28}$ Any disagreement in these 
processes was resolved through discussion between the reviewers. Extracted data included the first author name, publication year, study location, study design, the number of participants and their demographic features, comparative groups, prognostic factors, outcomes, methods for statistical analysis, summary statistics and items associated with a risk of bias. Authors were asked to provide missing data for relevant outcomes.

\section{Risk of bias in individual studies}

Risk of bias in individual studies was assessed by the Quality in Prognostic Studies tool. ${ }^{29}$ It consisted of six domains, which were rated as either low, moderate or high, and a study with low risk of bias in all domains was designated as a study with low risk of bias.

\section{Statistical analysis}

\section{Summary statistics}

If prognosis of IPAF was compared with that of CTD-IP or IIPs by the Kaplan-Meier survival curve and the log rank test, the result was to be converted into a hazard ratio (HR) if possible ${ }^{30}$ or otherwise the original data were presented. If the outcome was binary, the effect size of potential prognostic factors of IPAF was to be summarised as either an odds ratio (OR), risk ratio (RR) or HR. If the outcome or potential prognostic factors were continuous, they were to be summarised as the mean difference or the difference of the median value between two comparative groups, although there were no such cases in this review. The analysis focused only on a comparison of the prognosis and prognostic factors of IPAF reported in at least three studies given the assumption that frequent reports would indicate clinical relevance.

\section{Meta-analysis}

The results were combined only if the effect of a certain potential prognostic factor had been reported for the same outcome with the same summary statistics in at least three studies. Only univariate results were combined if the meta-analysis was appropriate because multivariate results were derived from different models constructed with multiple variables, which were diverse between studies. Meta-analysis was performed by a randomeffects model with the DerSimonian and Laird method ${ }^{31}$ using the statistical software Review Manager (RevMan) V.5.3 (Copenhagen: The Nordic Cochrane Centre, The Cochrane Collaboration, 2014). All of the results were presented with the $95 \%$ confidence interval (CI) in conjunction with the $95 \%$ prediction interval (PI), which was calculated if a meta-analysis was conducted and there was heterogeneity between studies. ${ }^{32}$ Statistical significance was set at $\mathrm{p}<0.05$.

\section{Heterogeneity and additional analysis}

Heterogeneity was assessed by the $Q$ statistic and I square. Statistical significance of heterogeneity was set at $\mathrm{p}<0.1$, and the magnitude was interpreted as not important $(0 \%-30 \%)$, moderate $(30 \%-50 \%)$, substantial $(50 \%-$ $70 \%)$ or considerable $(70 \%-100 \%){ }^{33}$
IPAF was likely to include a heterogeneous group of patients because it was diagnosed based on a combination of positive features in multiple domains. ${ }^{15}$ A different combination of positivity may have yielded a group with different clinical characteristics. Furthermore, a different number of cases with a usual interstitial pneumonia (UIP) pattern in IPAF was thought to affect the clinical course of the disease because UIP was noted to demonstrate a poor prognosis compared with other radiological and/or pathological patterns of IIPs. ${ }^{34}$ Therefore, the results were to be reanalysed depending on the proportion of radiological and/or pathological UIP pattern if data were available. Another subgroup analysis was also considered based on studies with a similar combination of positive domains, which contributed to the diagnosis of IPAF. Sensitivity analysis was to be conducted focusing on studies with low risk of bias alone. Small study bias including publication bias was to be examined graphically by a funnel plot and statistically by the Egger's test if 10 or more studies were available for meta-analysis. The test was to be performed using Stata V.14 (STATA Corp LLC) with statistical significance of $\mathrm{p}<0.1 .^{35}$

\section{Confirmation of prognostic factors}

Prognostic factors were confirmed based on the results of multivariate analyses. If the effect of a potential prognostic factor demonstrated the same trend in all studies and was significant in the majority of multiple studies $(>50 \%)$, it was deemed as a prognostic factor.

\section{Assessment of quality of presented evidence}

The Grades of Recommendation, Assessment, Development, and Evaluation (GRADE) system was applied to evaluate the quality of evidence regarding identified prognostic factors of IPAF. ${ }^{36}$

\section{RESULTS}

\section{Search and selection of eligible reports}

After removing 181 duplicates from a total of 656 records retrieved through a search of 4 electronic databases, 475 records were screened by the titles and abstracts, which identified 109 ineligible articles composed of case reports $(n=8)$, conference abstracts $(n=58)$, letters or editorials $(\mathrm{n}=27)$, non-English reports $(\mathrm{n}=5)$ and review articles $(n=11)$. After 335 more records were excluded due to irrelevant subjects, the remaining 31 records were retrieved as full texts, and finally 12 reports/studies were eligible for this study (figure 1). Among them, three studies were conducted by the same research group. No additional study was identified by searching the reference lists or cross referencing of eligible reports and relevant review articles.

\section{Characteristics of included studies}

All studies were of retrospective cohort design (table 1). In seven studies, all types of IPs were screened to identify cases of IPAF (Chung et al, ${ }^{37}$ Oldham et al, ${ }^{38}$ Adegunsoye et $a l,{ }^{39}$ Ahmad et $a l,{ }^{40}$ Collins et al,,$^{41}$ Dai $e t a l,{ }^{42}$ Lim et at $\left.{ }^{43}\right)$, whereas in two studies, IPAF was selected from cases of IP 


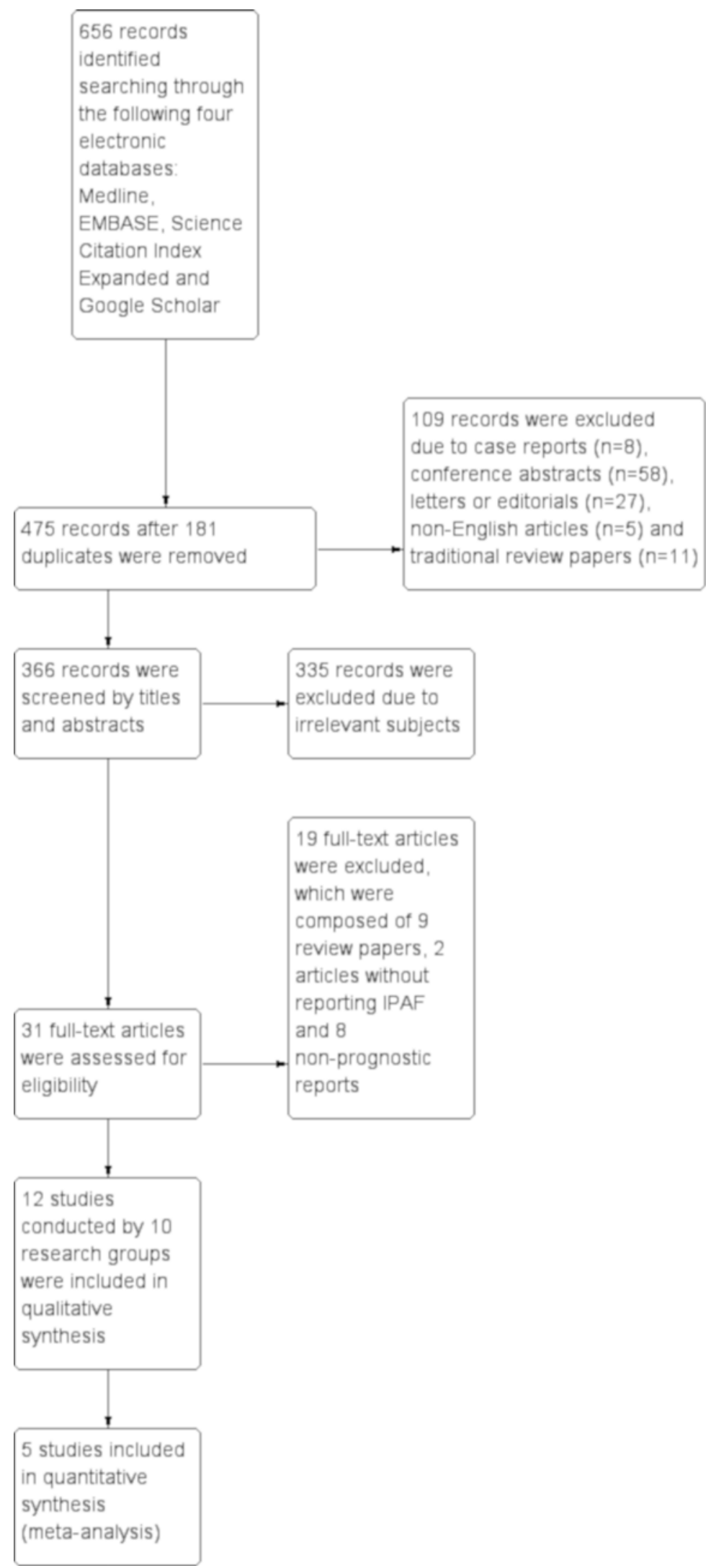

Figure 1 Study flow diagram A total of 656 records were retrieved through a search of four electronic databases, Medline, EMBASE, Science Citation Index Expanded, and Google Scholar. After removing 181 duplicates, 475 records were screened by titles and abstracts, which identified 109 ineligible articles composed of case reports $(n=8)$, conference abstracts $(n=58)$, letters or editorials $(n=27)$, non-English reports $(n=5)$ and review articles $(n=11)$. After 335 more records were excluded due to irrelevant subjects, the remaining 31 records were retrieved as full texts, and finally 12 reports/studies, which included 3 studies conducted by the same research group, were eligible for this study. IPAF, interstitial pneumonia with autoimmune features. 


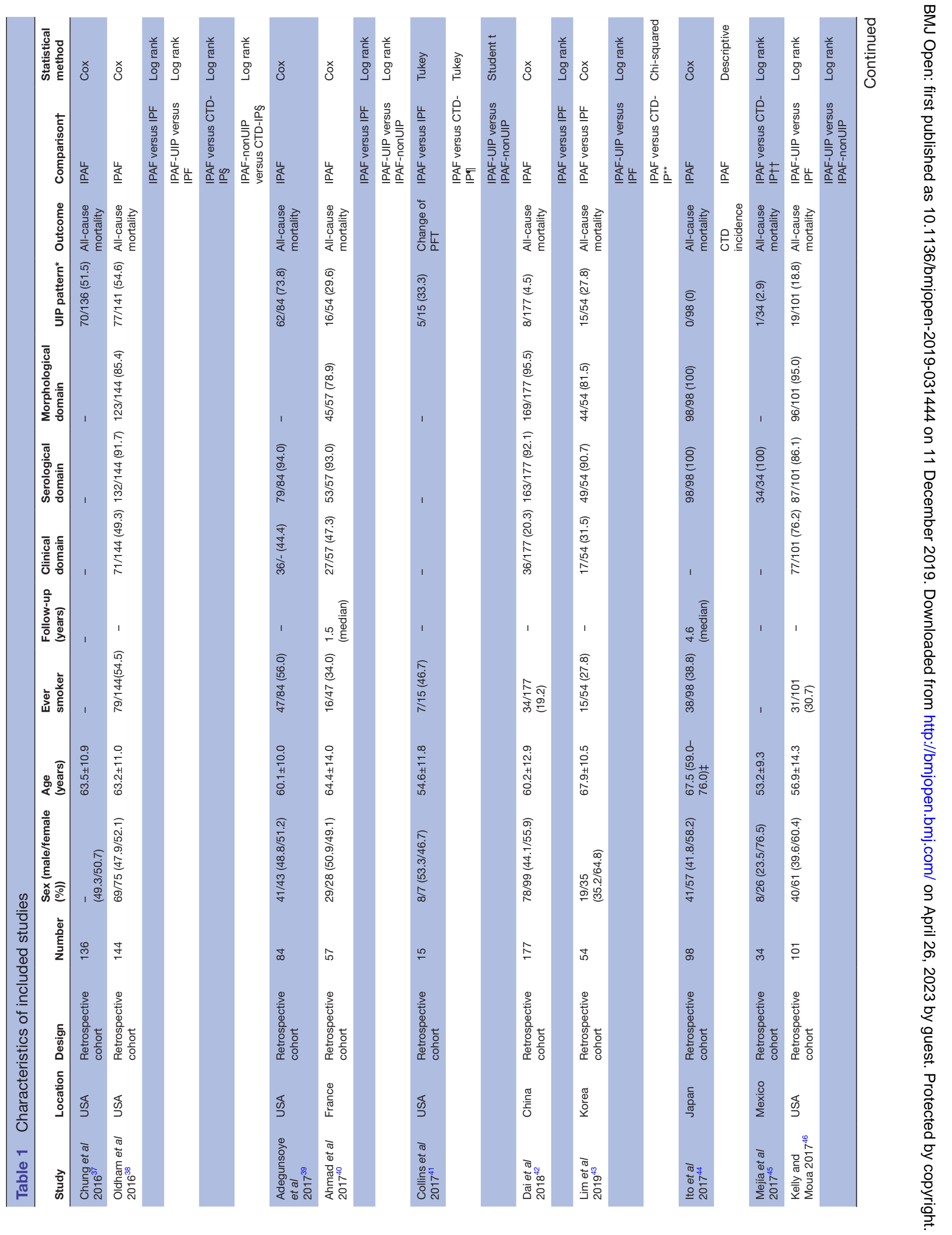




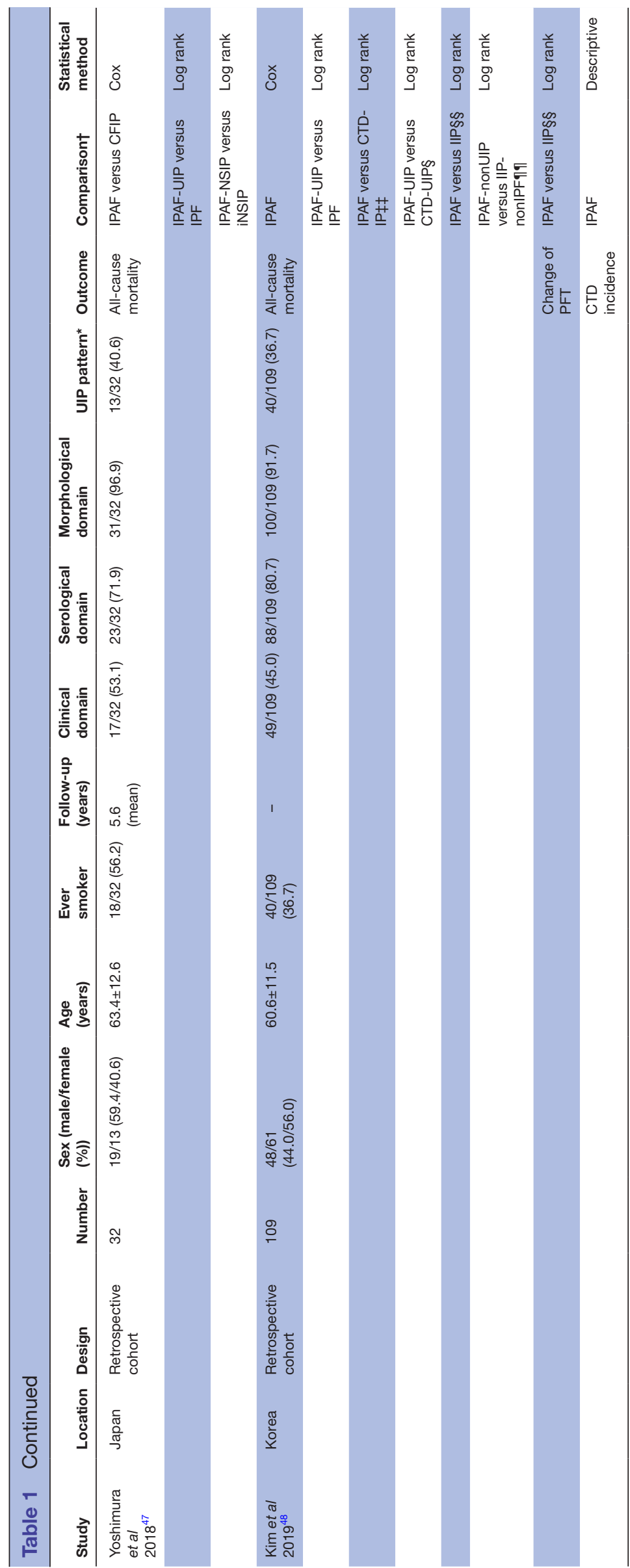

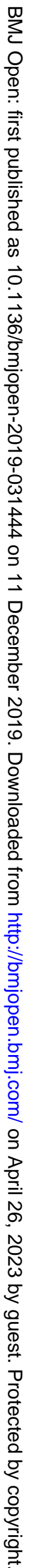


Table 2 Risk of bias in included studies

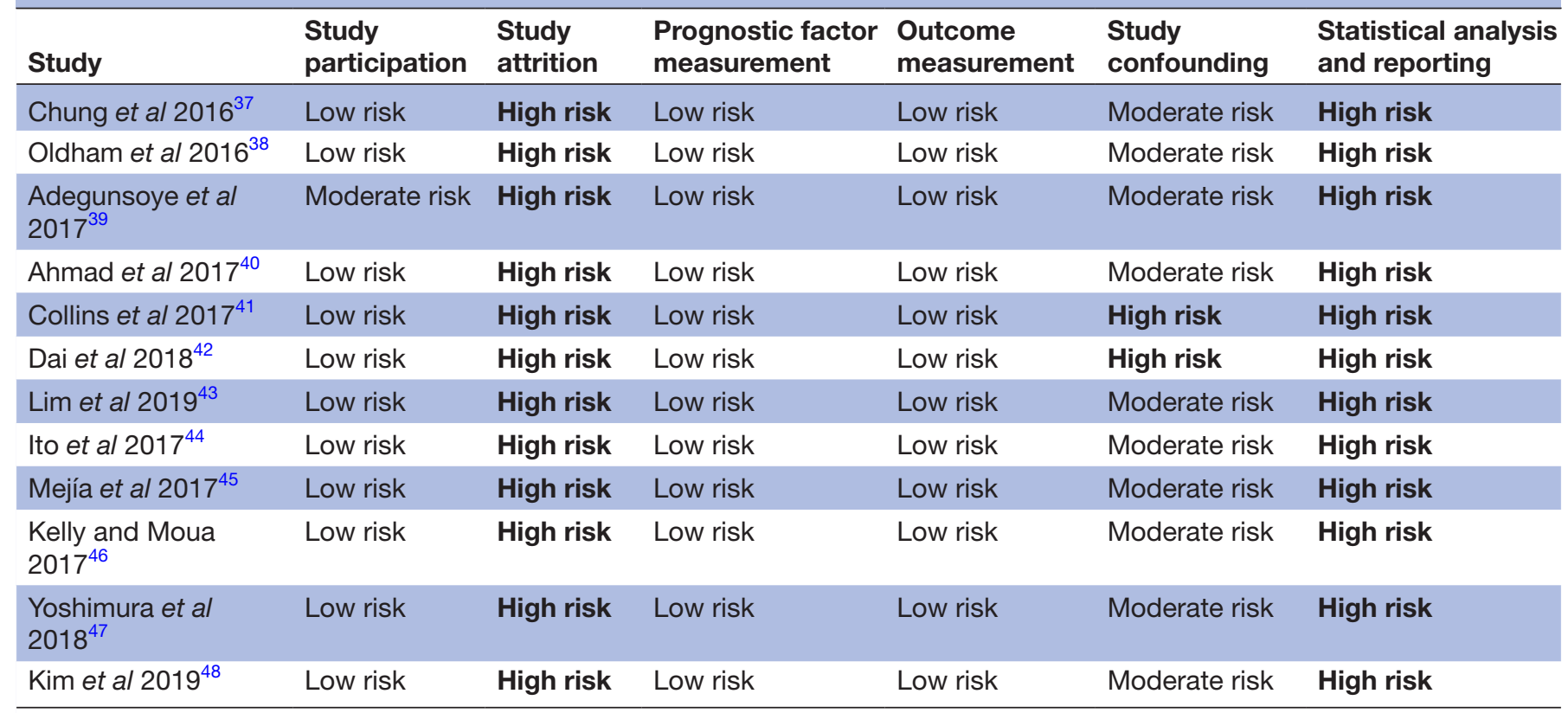

Bold text indicates high risk of bias.

with positive serology of IPAF classification criteria and myositis-specific autoantibodies, respectively (Ito $e t a l,{ }^{44}$ Mejía $e t a l^{45}$ ). The other three studies identified cases of IPAF from a cohort of UCTD-IP, chronic fibrosing interstitial pneumonia (CFIP) and IIPs, respectively (Kelly and Moua, ${ }^{46}$ Yoshimura et $a l,{ }^{47}$ Kim et $\left.a t^{48}\right)$.

The mean or median follow-up period was reported in only three studies, which spanned over $1.5-5.6$ years. The number of participants ranged from 15 to 177 , and their mean or median ages were between 53.2 and 67.9 years. The proportion of men and ever smokers was distributed between $23.5 \%$ and $59.4 \%$ and $19.2 \%$ and $56.2 \%$, respectively. Positivity of clinical, serological and morphological domains of IPAF classification criteria ranged from $20.3 \%$ to $76.2 \%, 71.9 \%$ to $100 \%$ and $78.9 \%$ to $100 \%$, respectively. UIP pattern was confirmed on a high-resolution computed tomography (HRCT) scan and/or a surgical lung biopsy (SLB) for between $0 \%$ and $73.8 \%$ of cases of IPAF. All-cause mortality was the primary outcome in all studies except for one (table 1).

\section{Risk-of-bias assessment}

All studies included in the review were deemed as containing some risk of bias. In particular, study attrition and statistical analysis were designated as a high risk of bias. The attrition of participants over time was unclear in all studies. Statistical analysis and reporting were also insufficient due to the lack of explanation of the analytical strategy and model development (table 2).

\section{Prognosis of IPAF in comparison to other IPs}

All-cause mortality of IPAF was significantly better than that of IPF in two studies (Dai et al, ${ }^{42}$ Lim et $a t^{43}$ ) ( $19.8 \%$ vs $31.9 \%, \mathrm{p}<0.001$ and $27.8 \%$ vs $63.4 \%, \mathrm{p}=0.008$, respectively), which included UIP pattern on HRCT in $4.5 \%$ and $27.8 \%$ of the cases, respectively (table 3 ). However, there was no significant difference of allcause mortality in the other two studies (Oldham $e a{ }^{38}$ Ahmad et $\left.a t^{40}\right)$, which included a larger number of cases with UIP pattern on HRCT $(54.6 \%$ and $29.6 \%$, respectively). There was no significant difference of all-cause mortality between IPAF-UIP and IPF in all five studies that reported it (Oldham et al, ${ }^{38}$ Lim et $a l,{ }^{43}$ Kelly and Moua, ${ }^{46}$ Yoshimura et $a l,{ }^{47}$ Kim et $a l^{48}$; table 3). Among the four studies comparing IPAF with CTD-IP, only one study $\left(\right.$ Oldham $\left.e t a l^{38}\right)$ demonstrated higher all-cause mortality for IPAF $(p<0.001)$. It included a larger proportion of a radiological and/or pathological UIP pattern (54.6\%) in contrast to $27.8 \%, 2.9 \%$ and $36.7 \%$ in the other three studies (Lim et $a l,{ }^{43}$ Mejía $e t a l,{ }^{45} \mathrm{Kim}$ et $a l^{48}$ ), respectively.

\section{Univariate analysis of potential prognostic factors}

Age, men, ever smokers, radiological and/or pathological UIP pattern, percentage of predicted forced vital capacity $(\% \mathrm{FVC})$, and percentage of predicted diffusing capacity of the lung for carbon monoxide (\% DLCO) were identified as potential prognostic factors for all-cause mortality of IPAF, which were reported in at least three studies (table 4).

Age was significantly associated with all-cause mortality of IPAF in all four studies that reported it (Oldham et al, ${ }^{38}$ Dai $e$ e $a l_{,}^{42}$ Ito $e t a l,{ }^{44} \mathrm{Kim}$ et $a l^{48}$; table 4$)$, which produced a combined effect of an HR of 1.06 (95\% CI 1.04 to 1.07) with no heterogeneity (figure 2). There was also a trend of worse all-cause mortality for men than women in all of these studies, which generated a significant result by a pooled analysis with an HR of 1.66 (95\% CI 1.22 to 2.25) 
Table 3 All-cause mortality of interstitial pneumonia with autoimmune features (IPAF) compared with other interstitial pneumonias*

\begin{tabular}{|c|c|c|}
\hline & Study & Effect size $^{\dagger}$ \\
\hline \multirow[t]{4}{*}{ IPAF versus IPF } & Oldham et al $2016^{38}$ & $\mathrm{P}=0.07$ (log rank) \\
\hline & Ahmad et al $2017^{40}$ & $\begin{array}{l}16.4 \% \text { versus } \\
5.2 \%, p=0.05 \text { (log } \\
\text { rank) }\end{array}$ \\
\hline & Dai et al $2018^{42}$ & $\begin{array}{l}19.8 \% \text { versus } \\
31.9 \%, p<0.001 \\
\text { (log rank) }\end{array}$ \\
\hline & Lim et al $2019^{43}$ & $\begin{array}{l}27.8 \% \text { versus } \\
63.4 \%, p=0.008 \\
(\text { Cox) }\end{array}$ \\
\hline
\end{tabular}

\begin{tabular}{|c|c|c|}
\hline \multirow{5}{*}{$\begin{array}{l}\text { IPAF-UIP } \\
\text { versus IPF }\end{array}$} & Oldham et al $2016^{38}$ & $\mathrm{P}=0.51$ (log rank) \\
\hline & Lim et al $2019^{43}$ & $\begin{array}{l}\text { Mean ST } 64.6 \\
\text { versus } 52.0 \\
\text { months, } p=0.08 \\
\text { (log-rank) }\end{array}$ \\
\hline & $\begin{array}{l}\text { Kelly and Moua } \\
2017^{46}\end{array}$ & $\mathrm{P}=0.08$ (log rank) \\
\hline & $\begin{array}{l}\text { Yoshimura et al } \\
2018^{47}\end{array}$ & $\mathrm{P}=0.09$ (log rank) \\
\hline & Kim et al $2019^{48}$ & $\begin{array}{l}\text { Median ST } 36 \\
\text { versus } 51 \text { months, } \\
p=0.43 \text { (log rank) }\end{array}$ \\
\hline \multirow[t]{4}{*}{$\begin{array}{l}\text { IPAF versus } \\
\text { CTD-IP }\end{array}$} & Oldham et al $2016^{38}$ & $\begin{array}{l}P<0.001 \text { (log } \\
\text { rank)§ }\end{array}$ \\
\hline & Lim et al $2019^{43}$ & $\begin{array}{l}27.8 \% \text { versus } \\
21.1 \%, p=0.41 \\
\text { (Fisher) }\end{array}$ \\
\hline & Mejía et al $2017^{45}$ & $\mathrm{P}>0.83$ (log rank) \\
\hline & Kim et al $2019^{48}$ & $\begin{array}{l}\text { Median ST } 160 \\
\text { versus } 142 \\
\text { months, } p=0.98 \\
\text { (log rank) }\end{array}$ \\
\hline
\end{tabular}

${ }^{*}$ Only a comparison of all-cause mortality of IPAF with that of other interstitial pneumonias, which was reported in at least three studies, was summarised. Italic bold indicates statistical significance.

tOnly $p$ value was described if effect estimates were not available. fUIP pattern was diagnosed based on radiological and/or pathological findings in two studies (Kelly and Moua, ${ }^{46} \mathrm{Kim}$ et $a l^{48}$ ) whereas it was determined radiologically in the other studies (Oldman et al, ${ }^{38}$ Lim et $a l,{ }^{42}$ Yoshimura et a ${ }^{47}$ ).

§IPAF demonstrated a higher mortality than CTD-IP. CTD-IP, connective tissue disease-associated interstitial pneumonia; IPF, idiopathic pulmonary fibrosis; ST, survival time; UIP, usual interstitial pneumonia.

with no heterogeneity (figure 3 ). The effect of a smoking habit was reported in five studies (Oldham et al, ${ }^{38} \mathrm{Ahmad}$ et $a l,{ }^{40}$ Dai $e t a l,{ }^{42}$ Ito $e t a l,{ }^{44}$ Kim $e t ~ a l^{48}$; table 4$)$, and a pooled analysis of these studies demonstrated that ever smokers were not significantly associated with all-cause mortality with an HR of 1.54 (95\% CI 0.97 to 2.46) and substantial heterogeneity (figure 4). One study (Oldham et $a l^{38}$ ) demonstrated the opposite effect to the others and seemed to be responsible for some of the heterogeneity. A UIP pattern was noted in the majority of IPAF $(54.6 \%)$ in that study in contrast to the other four studies, which demonstrated the proportion of UIP pattern as $29.6 \%$, $4.5 \%, 0 \%$ and $36.7 \%$, respectively. The effect of a radiological and/or pathological UIP pattern was reported in six studies (table 4). Because Oldham $e t a \hat{l}^{38}$ and Adegunsoye $e t a l^{39}$ were conducted by the same research group sharing the same cohort, the former study was prioritised for the analysis considering its larger sample size. A pooled analysis of three out of these five studies (Oldham et $a l,^{38}$ Dai $e t a l,{ }^{42} \mathrm{Kim}$ et $\left.a l^{48}\right)$ demonstrated that a radiological and/or pathological UIP pattern was significantly associated with all-cause mortality of IPAF with an HR of 2.93 (95\% CI 1.65 to 5.20$)$ and moderate heterogeneity (figure 5). Only one study (Dai et $a t^{42}$ ) demonstrated a non-significant result, and it included the least proportion $(4.5 \%)$ of IPAF subjects with a radiological and/or pathological UIP pattern in contrast to $54.6 \%$ and $36.7 \%$ in the other two studies (Oldham $e t a l^{88}$ and Kim $e t a l^{48}$ ), respectively. A pooled analysis of three studies (Oldham et $a l^{38}{ }^{38}$ Ito $e t a l^{4}$ and Kim $e t a l^{48}$ ) demonstrated that both $\% \mathrm{FVC}$ and \%DLCO were significantly associated with allcause mortality of IPAF with HRs of 0.89 (95\% CI 0.81 to 0.98 ) and 0.77 (95\% CI 0.69 to 0.85 ), respectively, with no heterogeneity (figures 6 and 7 ).

\section{Multivariate analysis of potential prognostic factors}

The adjusted effect of age on all-cause mortality of IPAF was reported in four studies, all of which demonstrated significant results and almost the same effect size with HRs ranging from 1.04 to 1.07 (table 4). Men were not significantly associated with all-cause mortality with an HR of 1.65 (95\% CI 0.92 to 2.97) in one study (Oldham et $\left.a l^{38}\right)$. The adjusted effect of smoking habit on all-cause mortality was reported in two studies. One of these studies showed a significant result with an HR of 2.11 (95\% CI 1.02 to 4.36; Dai $e t a t^{42}$ ), whereas the other study showed a non-significant result with an HR of 1.11 (95\% CI 0.60 to 2.05; Oldham $\left.e t a l^{38}\right)$. The effect of a radiological and/or pathological UIP pattern was reported using multivariate analyses in three studies (Oldham $e t a l l^{38}$, Adegunsoye $e t$ $a l^{39}$ and Kim $\left.e t a l^{48}\right)$. Oldham $e t a l^{8}$ was prioritised over Adegunsoye $e t a \vec{l}^{39}$ for the analysis considering its larger sample size in the same cohort, which demonstrated a non-significant result with an HR of 1.72 (95\% CI 0.83 to 3.56). However, another study (Kim et $a l^{48}$ ) reported a significantly worse all-cause mortality with a radiological and/or pathological UIP pattern with an HR of 3.85 (95\% CI 1.99 to 7.43 ). The effect of $\% \mathrm{FVC}$ and \%DLCO was reported using a multivariate analysis in only one study each. There was no significant association between $\% \mathrm{FVC}$ and all-cause mortality with an HR of $1.00(95 \%$ CI 0.78 to 1.29 ; Oldham $e$ e $a \hat{l}^{8}$; table 4 ), whereas \%DLCO was significantly associated with all-cause mortality with an HR of 0.66 (95\% CI 0.57 to 0.78 ; Kim et $a l^{48}$; table 4). 
Table 4 Potential prognostic factors for interstitial pneumonia with autoimmune features (IPAF)*

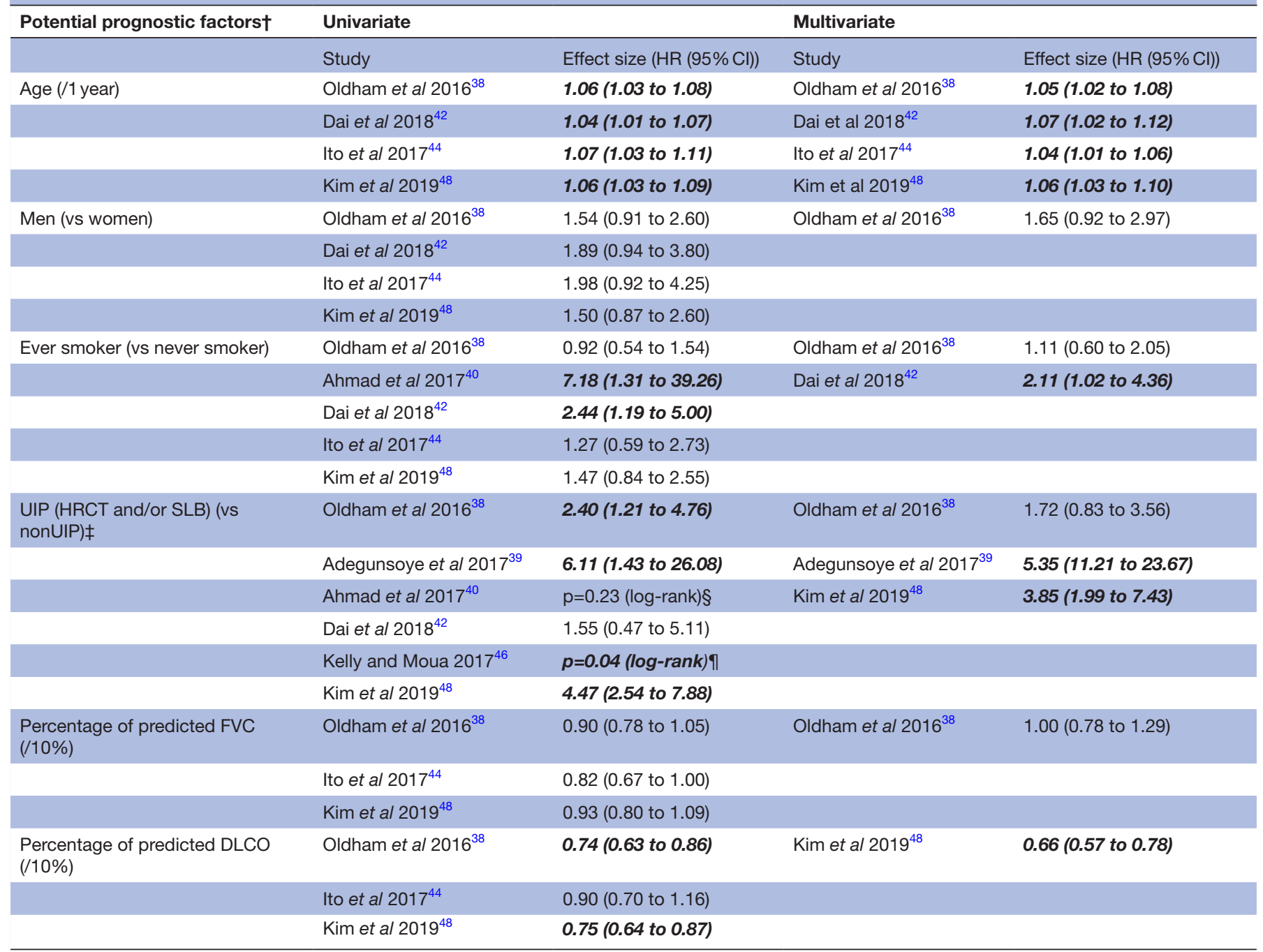

*Italic bold indicates statistical significance.

†Potential prognostic factors were defined as any clinical information that was reported by at least three studies.

fUIP pattern was confirmed based on the finding of HRCT scan in three studies (Oldham et al, ${ }^{38}$ Ahmad et al, ${ }^{40}$ Dai et al, ${ }^{42}$ ), pathological finding in one study (Adegunsoye et $\mathrm{al}^{39}$ ) and either findings in two studies (Kelly and Moua, ${ }^{46} \mathrm{Kim}$ et $\mathrm{al},{ }^{4848}$ ).

$\S$ Survival was estimated by the Kaplan-Meier survival curve and the log-rank test demonstrated that the prognosis of IPAF-UIP tended to be worse than that of IPAF-nonUIP.

ISurvival was estimated by the Kaplan-Meier survival curve and the log-rank test demonstrated that the prognosis of IPAF-UIP was significantly worse than that of IPAF-nonUIP.

DLCO, diffusing capacity of the lung for carbon monoxide; FVC, forced vital capacity; HRCT, high-resolution computed tomography; SLB, surgical lung biopsy; UIP, usual interstitial pneumonia.

Hazard Ratio

\begin{tabular}{|c|c|c|c|c|}
\hline Study or Subgroup & log[Hazard Ratio] & SE & Weight & IV, Random, $95 \% \mathrm{Cl}$ \\
\hline Dai2018 & 0.04 & 0.013 & $32.5 \%$ & $1.04[1.01,1.07]$ \\
\hline Ito 2017 & 0.068 & 0.019 & $15.2 \%$ & $1.07[1.03,1.11]$ \\
\hline Kim2019 & 0.059 & 0.014 & $28.0 \%$ & $1.06[1.03,1.09]$ \\
\hline Oldman 2016 & 0.058 & 0.015 & $24.4 \%$ & $1.06[1.03,1.09]$ \\
\hline Total $(95 \% \mathrm{Cl})$ & & & $100.0 \%$ & $1.06[1.04,1.07]$ \\
\hline
\end{tabular}

Hazard Ratio IV, Random, $95 \% \mathrm{Cl}$

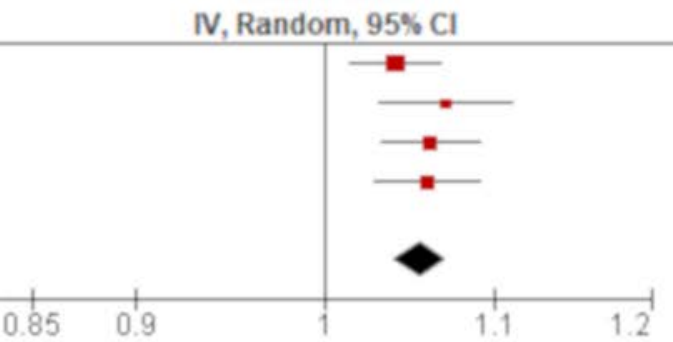

Figure 2 Forrest plot of the effect of age on all-cause mortality of interstitial pneumonia with autoimmune features. The effect of age on all-cause mortality was reported in four studies, in which a total of 528 participants with 236 men (44.7\%) were included. Meta-analysis of these studies demonstrated that age was significantly associated with all-cause mortality with an HR of $1.06(95 \% \mathrm{Cl} 1.04$ to $1.07, \mathrm{p}<0.00001)$ with no heterogeneity. 
Hazard Ratio

\begin{tabular}{|c|c|c|c|c|}
\hline Study or Subgroup & $\log [$ Hazard Ratio] & SE & Weight & IV, Random, $95 \% \mathrm{Cl}$ \\
\hline Dai2018 & 0.64 & 0.36 & $18.9 \%$ & $1.90[0.94,3.8$ \\
\hline Ito 2017 & 0.68 & 0.39 & $16.1 \%$ & $1.97[0.92,4.24]$ \\
\hline Kim2019 & 0.41 & 0.28 & $31.3 \%$ & $1.51[0.87,2.6$ \\
\hline Oldman2016 & 0.43 & 0.27 & $33.7 \%$ & $1.54[0.91,2$ \\
\hline Total $(95 \%$ Cl) & & & $100.0 \%$ & $1.66[1.22,2.2$ \\
\hline
\end{tabular}

Hazard Ratio IV, Random, $95 \% \mathrm{Cl}$

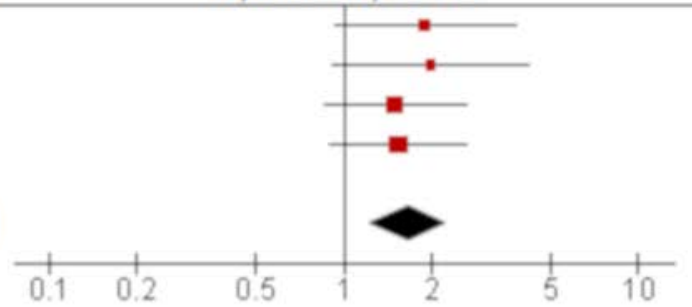

Figure 3 Forrest plot of the effect of sex on all-cause mortality of interstitial pneumonia with autoimmune features. The effect of sex on all-cause mortality was reported in four studies, in which a total of 528 participants with 236 men (44.7\%) were included. Meta-analysis of these studies demonstrated that all-cause mortality of men was significantly worse than that of women with an HR of $1.66(95 \% \mathrm{Cl} 1.22$ to $2.25, \mathrm{p}=0.001)$ with no heterogeneity.

\section{Additional analysis}

Neither a subgroup analysis nor sensitivity analysis was conducted due to the small number of studies and some risk of bias identified in all studies. Small study bias could not be examined due to the small number of studies.

\section{Confirmation of prognostic factors}

Among six potential prognostic factors identified, only age was deemed to contribute to all-cause mortality of IPAF. It was significant by multivariate analysis in all studies, and all of the results showed a similar trend.

\section{Quality of evidence}

Quality of evidence for age as a prognostic factor for IPAF was rated as very low by the GRADE system (table 5 ).

\section{DISCUSSION}

This systematic review and meta-analysis demonstrated that the clinical features of IPAF, such as demographics, number of cases with a UIP pattern and positivity of each domain constituting the classification criteria of IPAF, were diverse between studies. All-cause mortality of IPAF-UIP was not significantly different from that of IPF in all studies, although the prognosis of IPAF in comparison to IPF or CTD-IP was inconsistent between studies and seemed to have been related to the proportion of cases with a radiological and/or pathological UIP pattern. Only age was deemed as a prognostic factor for all-cause mortality of IPAF based on multivariate results, although sex, smoking habit, radiological and/or pathological UIP pattern, \%FVC and \%DLCO were also considered as potential prognostic factors.

The variability of clinical features of IPAF between studies was described in a previous review. ${ }^{17}$ It may be mostly related to the retrospective design of studies and a different process of identifying cases of IPAF. In seven studies, all types of IP were screened to identify cases of IPAF, whereas two studies sought to identify IPAF from cases of IP with positive serology of IPAF classification criteria and myositis-specific autoantibodies, respectively. The other three studies identified cases of IPAF from UCTD-IP, CFIP and IIPs, respectively. As a result, this potential selection bias may have caused clinical heterogeneity between the studies in this review. The presence of a radiological and/or pathological UIP pattern is particularly important for the analysis of prognosis of IPAF because it is reported to be predictive of a worse prognosis of IIPs. ${ }^{49}$ It is still unclear whether IPAF represents

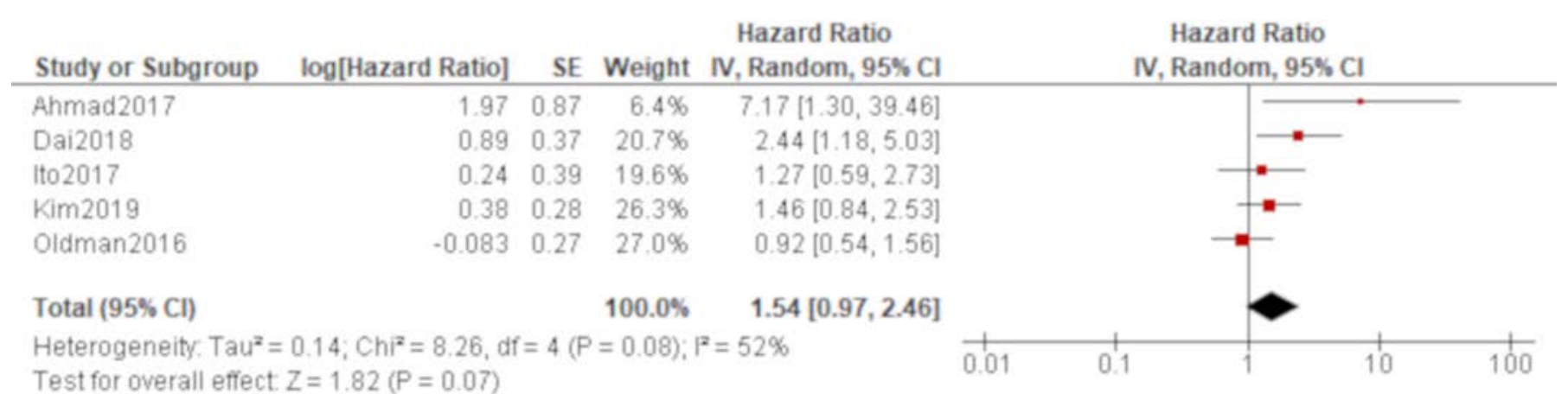

Figure 4 Forrest plot of the effect of smoking habit on all-cause mortality of interstitial pneumonia with autoimmune features. The effect of smoking habit was reported in five studies, in which a total of 585 participants with 265 men (45.3\%) were included. Meta-analysis of these studies demonstrated that ever smokers were not significantly associated with allcause mortality with an HR of $1.54(95 \% \mathrm{Cl} 0.97$ to $2.46, \mathrm{p}=0.07 / 95 \%$ prediction interval 0.37 to 6.33$)$. There was substantial heterogeneity between the results of the included studies $\left(\chi^{2}=8.26, d f=4, p=0.08, l^{2}=52 \%\right)$. Only one study (Oldham et a $\left.\left.\right|^{38}\right)$ demonstrated an opposite effect to the others, and the majority of participants were ever smokers with a radiological usual interstitial pneumonia pattern in that study. 
Hazard Ratio

Study or Subgroup log[Hazard Ratio] SE Weight IV, Random, $95 \% \mathrm{Cl}$

$\begin{array}{lllll}\text { Dai2018 } & 0.438 & 0.609 & 17.9 \% & 1.55[0.47 .5 .11]\end{array}$

Kim2019

Oldman2016

$\begin{array}{llll}1.498 & 0.289 & 44.8 \%\end{array}$

$0.875 \quad 0.349 \quad 37.3 \%$
$4.47[2.54,7.88]$

$2.40[1.21,4.75]$
Hazard Ratio IV, Random, $95 \% \mathrm{Cl}$

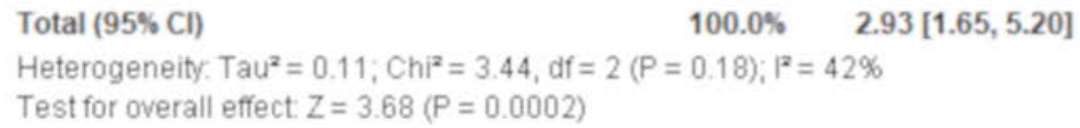

Figure 5 Forrest plot of the effect of a usual interstitial pneumonia (UIP) pattern on a high-resolution computed tomography (HRCT) and/or a surgical lung biopsy (SLB) specimen on all-cause mortality of interstitial pneumonia with autoimmune features (IPAF). The effect of UIP pattern on all-cause mortality was reported in six studies. Meta-analysis was conducted for three of these studies, in which a total of 430 participants with 195 men (45.3\%) were included. A UIP pattern on HRCT and/or SLB was significantly associated with all-cause mortality of IPAF with an HR of $2.93(95 \% \mathrm{Cl} 1.65$ to $5.20, \mathrm{p}=0.0002 / 95 \%$ prediction interval 0.01 to 808.7). There was moderate heterogeneity between the results of the included studies $\left(\chi^{2}=3.44, d f=2, p=0.18\right.$, $\left.1^{2}=42 \%\right)$. Only one study (Dai et a $\left.\right|^{42}$ ) demonstrated a non-significant result, and it included the least proportion (4.5\%) of IPAF subjects with a radiological and/or pathological UIP pattern in contrast to $54.6 \%$ and $36.7 \%$ in the other two studies (Oldham et $a l^{38}$ and Kim et $\left.a^{48}\right)$, respectively.

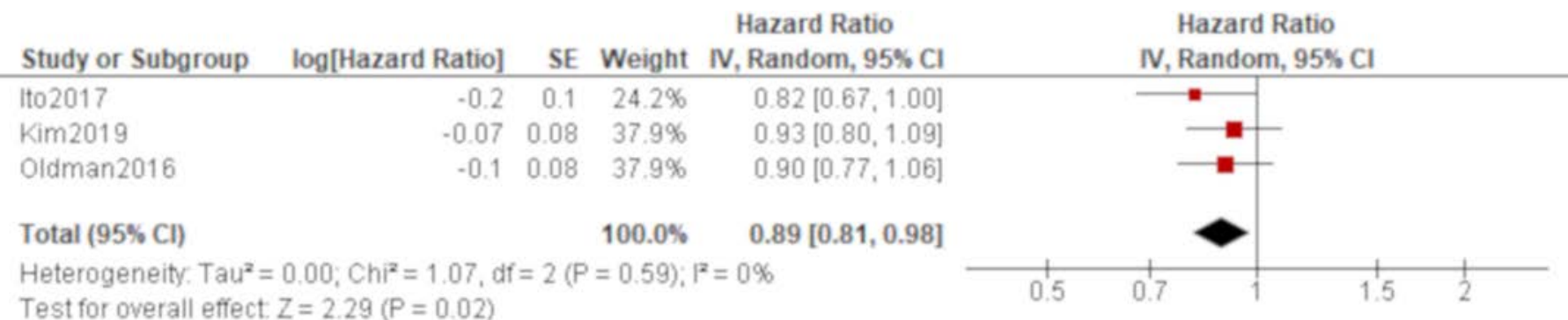

Figure 6 Forrest plot of the effect of percentage of predicted forced vital capacity (\%FVC) on all-cause mortality of interstitial pneumonia with autoimmune features (IPAF). The effect of \%FVC on all-cause mortality was reported in three studies, in which a total of 351 participants with 158 men (45.0\%) were included. Meta-analysis of these studies demonstrated that \%FVC was significantly associated with all-cause mortality of IPAF with an HR of $0.89(95 \% \mathrm{Cl} 0.81$ to $0.98, p=0.02)$ with no heterogeneity.

\begin{tabular}{|c|c|c|c|c|c|c|c|c|}
\hline Study or Subgroup & log[Hazard Ratio] & SE & Weight & $\begin{array}{l}\text { Hazard Ratio } \\
\mathrm{IV}, \text { Random, } 95 \% \mathrm{Cl}\end{array}$ & \multicolumn{3}{|c|}{$\begin{array}{l}\text { Hazard Ratio } \\
\text { IV, Random, } 95 \% \text { Cl }\end{array}$} & \\
\hline Ito 2017 & -0.1 & 0.13 & $15.9 \%$ & $0.90[0.70,1.17]$ & & $\longrightarrow$ & & \\
\hline Kim2019 & -0.29 & 0.08 & $42.0 \%$ & $0.75[0.64,0.88]$ & & $\square$ & & \\
\hline Oldman2016 & -0.3 & 0.08 & $42.0 \%$ & $0.74[0.63,0.87]$ & & $\square$ & & \\
\hline Total $(95 \%$ Cl) & & & $100.0 \%$ & $0.77[0.69,0.85]$ & & & & \\
\hline \multicolumn{5}{|c|}{$\begin{array}{l}\text { Heterogeneity, } \operatorname{Tau}^{2}=0.00 ; \mathrm{Chi}^{2}=1.90, \mathrm{df}=2(\mathrm{P}=0.39) ; \mathrm{I}^{2}=0 \% \\
\text { Test for overall effect } Z=5.09(\mathrm{P}<0.00001)\end{array}$} & 0.5 & 0.7 & 1.5 & 2 \\
\hline
\end{tabular}

Figure 7 Forrest plot of the effect of percentage of diffusing capacity of the lung for carbon monoxide (\%DLCO) on all-cause mortality of interstitial pneumonia with autoimmune features (IPAF). The effect of \%DLCO on all-cause mortality was reported in three studies, in which a total of 351 participants with 158 men (45.0\%) were included. Meta-analysis of these studies demonstrated that \%DLCO was significantly associated with all-cause mortality of IPAF with an HR of $0.77(95 \% \mathrm{Cl} 0.69$ to $0.85, p<0.00001)$ with no heterogeneity.

a prodromal condition that could evolve into an overt CTD-IP or a new clinical entity that is different from CTD-IP or IIPs. If the former is the case, it is expected that IPAF-UIP would demonstrate a better prognosis than IPF because the prognosis of CTD-UIP was reported to be better than that of IPF. ${ }^{50}$ However, other reports also stated that rheumatoid arthritis-associated UIP (RA-UIP) would follow a similar prognosis as IPF. ${ }^{51}$ Therefore, the finding of this review that there was no significant difference of all-cause mortality between IPAF-UIP and IPF may be derived from the possibility that IPAF-UIP was a prodromal state for RA-UIP. In fact, IPAF was followed up to reveal the CTD incidence in two studies in this review, and the largest proportion of incident cases was demonstrated to be RA $(58.3 \%$ and $30.8 \%$, respectively; data not shown). However, this remains a speculation because no other studies have reported the development of defined CTDs. In addition, clinical information specific to RA such as anti-cyclic citrullinated peptide antibody ${ }^{52}$ was lacking. If the IPAF-UIP included in this review was positive for this autoantibody, it would likely have suggested underlying RA-UIP and reasonably explained the similar 


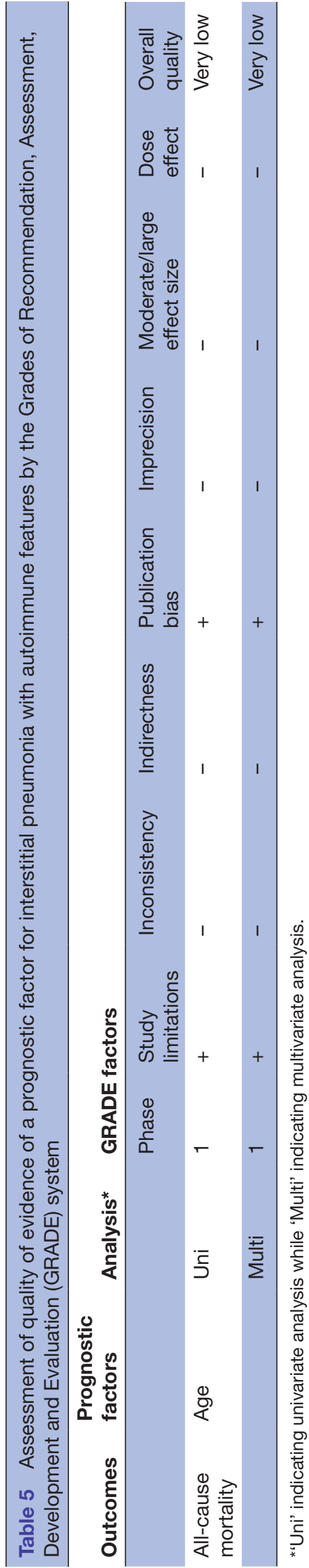

mortality as IPF. Further research is imperative to clarify the prognostic significance of a UIP pattern for IPAF compared with IPF and what IPAF-UIP represents.

Another important factor that may have affected the prognosis of IPAF is that cases of IPAF in this review may not necessarily represent an inception cohort because all studies were retrospectively conducted at a referral centre. ${ }^{53}$ As a result, some cases of IPAF with gradual progression may have been referred and enrolled for further investigation at an advanced stage, and this would have led to a biassed estimation of survival. In fact, only three studies described the follow-up period for IPAF, and it was reported as 1.5 years in one study. This period seems to be too short to estimate the prognosis of this disease group unless the rapidly progressive type of IP or acute exacerbation of the disease was the main subject of study. Therefore, it is important to enrol an inception cohort of IPAF to elucidate its prognosis in future research.

This systematic review clarified a prognostic factor for IPAF. Age was significantly associated with worse all-cause mortality of the disease in both univariate and multivariate analyses. This finding is consistent with previous reports of both $\mathrm{IPF}^{54}$ and other types of $\mathrm{IP}^{55}$ and can be explained by the fact that the number of comorbidities increases and pulmonary function deteriorates with age. Although sex, smoking habit, radiological and/or pathological UIP pattern, \%FVC and \%DLCO were not confirmed as prognostic factors due to non-significant or inconsistent results or a significant result in a single study by multivariate analyses, it is not pathophysiologically unreasonable to believe that these factors might have prognostic significance. Smoking habit is common for men and increases the risk of other comorbidities such as hypertension and other cardiovascular diseases, which can affect the overall mortality of the disease. Smoking may also cause emphysematous changes in pulmonary parenchyma combined with pulmonary fibrosis, making prognosis worse ${ }^{56}$ The presence of a radiological and/or pathological UIP pattern represents a progressive fibrotic process that is unfavourably responsive to traditional immunosuppressants although the prognostic difference between UIP and other IP patterns is not as obvious for CTD-IP as for IIPs. ${ }^{57}$ Furthermore, \%FVC and \%DLCO reflect the residual capacity of the lung, which may impact the prognosis of the disease.

The findings of prognostic factors in this review should be interpreted with caution. In particular, attention should be paid to the fact that significance was determined based on the results of multivariate analyses, which were conducted in only a few studies. As a result, some potential prognostic factors may possibly have been deemed as non-prognostic due to type 2 error in this review. Furthermore, any clinical information that was reported in fewer than three studies was excluded from further investigation for prognostic significance by assuming less clinical relevance. However, some clinical features of IPAF such as the positivity of clinical, serological and morphological domains still seem relevant to the prognosis of the disease. 
Further research needs to be conducted to address this issue. There were also other methodological limitations that affected the findings of this review. First, a subgroup analysis was not feasible due to a small number of studies, although there was clinical and methodological diversity between studies. The prognosis and prognostic factors of IPAF may probably be different depending on these various clinical features. However, at least the effect of age is likely to be true regardless of clinical diversity of IPAF because this finding was consistent between studies and no heterogeneity was identified in the meta-analysis. Second, all studies included in this review were affected by some risk of bias, and thus the quality of presented evidence was deemed as very low. Therefore, more primary studies of high quality need to be conducted to clarify the prognosis and prognostic factors of IPAF. Moreover, the current systematic review and meta-analysis should be updated with additional reports in sufficient numbers, and other outcomes of clinical relevance that were not addressed in this study, such as a progression of the disease and CTD incidence, should also be addressed in the future.

\section{CONCLUSIONS}

This systematic review and meta-analysis demonstrated that all-cause mortality of IPAF-UIP was not significantly different from that of IPF, although the prognosis of IPAF may be better if the proportion of a UIP pattern is small. Old age was significantly associated with worse all-cause mortality of IPAF.

Acknowledgements The authors would like to thank Cambridge English Correction Service for their professional proofreading.

Contributors HK planned the entire research project and analysed data. He also summarized the result and wrote the manuscript. He has full access to all of the data in the study and takes responsibility for the integrity of the data and the accuracy of the analysis.0MP made contributions in conceiving the research project. He was also engaged in literature search, data extraction and risk-of-bias assessment. He provided thoughts and opinions to a draft paper and approved of the final version of the manuscript.

Funding The authors have not declared a specific grant for this research from any funding agency in the public, commercial or not-for-profit sectors.

Competing interests None declared.

Patient consent for publication Not required.

Ethics approval It was waived as this study was only based on the summary result of previously published articles and individual patient data were not obtained or accessed.

Provenance and peer review Not commissioned; externally peer reviewed.

Data availability statement Data are available upon reasonable request.

Open access This is an open access article distributed in accordance with the Creative Commons Attribution Non Commercial (CC BY-NC 4.0) license, which permits others to distribute, remix, adapt, build upon this work noncommercially, and license their derivative works on different terms, provided the original work is properly cited, appropriate credit is given, any changes made indicated, and the use is non-commercial. See: http://creativecommons.org/ licenses/by-nc/4.0/.

\section{ORCID iD}

Hiroyuki Kamiya http://orcid.org/0000-0001-5623-1279
REFERENCES

1 Travis WD, Costabel U, Hansell DM, et al. An official American Thoracic Society/European Respiratory Society statement: update of the international multidisciplinary classification of the idiopathic interstitial pneumonias. Am J Respir Crit Care Med 2013;188:733-48.

2 Fischer A, du Bois R. Interstitial lung disease in connective tissue disorders. The Lancet 2012;380:689-98.

3 Gulati M, Redlich CA. Asbestosis and environmental causes of usual interstitial pneumonia. Curr Opin Pulm Med 2015;21:193-200.

4 Skeoch S, Weatherley N, Swift A, et al. Drug-induced interstitial lung disease: a systematic review. JCM 2018;7.

5 Park JH, Kim DS, Park IN, et al. Prognosis of fibrotic interstitial pneumonia: idioapthic versus collagen vascular disease-related subtypes. Am J Respir Crit Care Med 2007;175:705-11.

6 Tzelepis GE, Toya SP, Moutsopoulos HM. Occult connective tissue diseases mimicking idiopathic interstitial pneumonias. Eur Respir J 2008;31:11-20.

7 Homma Y, Ohtsuka Y, Tanimura K, et al. Can interstitial pneumonia as the sole presentation of collagen vascular diseases be differentiated from idiopathic interstitial pneumonia? Respiration 1995;62:248-51.

8 Fischer A, Pfalzgraf FJ, Feghali-Bostwick CA, et al. Anti-th/topositivity in a cohort of patients with idiopathic pulmonary fibrosis. $J$ Rheumatol 2006;33:1600-5.

9 Mosca M, Neri R, Bombardieri S. Undifferentiated connective tissue diseases (UCTD): a review of the literature and a proposal for preliminary classification criteria. Clin Exp Rheumatol 1999;17:615-20.

10 Suda T, Kono M, Nakamura Y, et al. Distinct prognosis of idiopathic nonspecific interstitial pneumonia (NSIP) fulfilling criteria for undifferentiated connective tissue disease (UCTD). Respir Med 2010;104:1527-34

11 Kinder BW, Collard HR, Koth L, et al. Idiopathic nonspecific interstitial pneumonia: lung manifestation of undifferentiated connective tissue disease? Am J Respir Crit Care Med 2007;176:691-7

12 Corte TJ, Copley SJ, Desai SR, et al. Significance of connective tissue disease features in idiopathic interstitial pneumonia. Eur Respir J 2012;39:661-8.

13 Fischer A, West SG, Swigris JJ, et al. Connective tissue diseaseassociated interstitial lung disease: a call for clarification. Chest 2010;138:251-6.

14 Vij R, Noth I, Strek ME. Autoimmune-featured interstitial lung disease: a distinct entity. Chest 2011;140:1292-9.

15 Fischer A, Antoniou KM, Brown KK, et al. An official European Respiratory Society/American Thoracic Society research statement: interstitial pneumonia with autoimmune features. Eur Respir $J$ 2015;46:976-87.

16 Chartrand S, Swigris JJ, Stanchev L, et al. Clinical features and natural history of interstitial pneumonia with autoimmune features: a single center experience. Respir Med 2016;119:150-4.

17 Sambataro G, Sambataro D, Torrisi SE, et al. State of the art in interstitial pneumonia with autoimmune features: a systematic review on retrospective studies and suggestions for further advances. Eur Respir Rev 2018;27.

18 Moher D, Liberati A, Tetzlaff J, et al. Preferred reporting items for systematic reviews and meta-analyses: the PRISMA statement. Ann Intern Med 2009;151:264-9.

19 Stroup DF, Berlin JA, Morton SC, et al. Meta-analysis of observational studies in epidemiology: a proposal for reporting. Meta-analysis of Observational Studies in Epidemiology (MOOSE) group. JAMA 2000;283:2008-12.

20 Aletaha D, Neogi T, Silman AJ, et al. Rheumatoid arthritis classification criteria: an American College of Rheumatology/ European League Against Rheumatism collaborative initiative. Ann Rheum Dis 2010;2010:1580-8.

21 van den Hoogen F, Khanna D, Fransen J, et al. Classification criteria for systemic sclerosis: an American College of Rheumatology/ European League Against Rheumatism collaborative initiative. Ann Rheum Dis 2013;2013:1747-55.

22 Tan EM, Cohen AS, Fries JF, et al. The 1982 revised criteria for the classification of systemic lupus erythematosus. Arthritis Rheum 1982;25:1271-7.

23 Vitali C, Bombardieri S, Jonsson R, et al. Classification criteria for Sjögren's syndrome: a revised version of the European criteria proposed by the American-European consensus group. Ann Rheum Dis 2002;61:554-8.

24 Smolen JS, Steiner G. Mixed connective tissue disease: to be or not to be? Arthritis Rheum 1998;41:768-77.

25 Bohan A, Peter JB. Polymyositis and dermatomyositis (first of two parts). New Engl J Med 1975;292:344-7. 
26 Assayag D, Kim EJ, Elicker BM, et al. Survival in interstitial pneumonia with features of autoimmune disease: a comparison of proposed criteria. Respir Med 2015;109:1326-31.

27 Haddaway NR, Collins AM, Coughlin D, et al. The role of Google Scholar in evidence reviews and its applicability to grey literature searching. PLoS One 2015;10:e0138237.

28 Kamiya H, Panlaqui OM. Prognostic significance of autoantibodies for idiopathic pulmonary fibrosis: protocol for a systematic review. BMJ Open 2018;8:e020862

29 Hayden JA, Côté P, Bombardier C. Evaluation of the quality of prognosis studies in systematic reviews. Ann Intern Med 2006;144:427-37.

30 Tierney JF, Stewart LA, Ghersi D, et al. Practical methods for incorporating summary time-to-event data into meta-analysis. Trials 2007;8:16.

31 DerSimonian R, Laird N. Meta-analysis in clinical trials. Control Clin Trials 1986;7:177-88.

32 Riley RD, Higgins JPT, Deeks JJ. Interpretation of random effects meta-analyses. BMJ 2011;342:d549.

33 Higgins JPT, Green S. Cochrane Handbook for Systematic Reviews of Interventions Version 5.1.0 [updated March 2011]. The Cochrane Collaboration 2011. Available: http://www. handbook.cochrane.org

34 Kim DS, Collard HR, King TE. Classification and natural history of the idiopathic interstitial pneumonias. Proc Am Thorac Soc 2006;3:285-92.

35 Egger M, Smith GD, Schneider M, et al. Bias in meta-analysis detected by a simple, graphical test. BMJ 1997;315:629-34.

36 Iorio A, Spencer FA, Falavigna M, et al. Use of grade for assessment of evidence about prognosis: rating confidence in estimates of event rates in broad categories of patients. BMJ 2015;350:h870

37 Chung JH, Montner SM, Adegunsoye A, et al. CT findings, radiologic-pathologic correlation, and imaging predictors of survival for patients with interstitial pneumonia with autoimmune features. AJR Am J Roentgenol 2017;208:1229-36.

38 Oldham JM, Adegunsoye A, Valenzi E, et al. Characterisation of patients with interstitial pneumonia with autoimmune features. Eur Respir J 2016;47:1767-75.

39 Adegunsoye A, Oldham JM, Valenzi E, et al. Interstitial pneumonia with autoimmune features: value of histopathology. Arch Pathol Lab Med 2017;141:960-9.

40 Ahmad K, Barba T, Gamondes D, et al. Interstitial pneumonia with autoimmune features: clinical, radiologic, and histological characteristics and outcome in a series of 57 patients. Respir Med 2017;123:56-62.

41 Collins BF, Spiekerman CF, Shaw MA, et al. Idiopathic interstitial pneumonia associated with autoantibodies: a large case series followed over 1 year. Chest 2017;152:103-12.

42 Dai J, Wang L, Yan X, et al. Clinical features, risk factors, and outcomes of patients with interstitial pneumonia with autoimmune features: a population-based study. Clin Rheumatol 2018;37:2125-32.
43 Lim JU, Gil BM, Kang HS, et al. Interstitial pneumonia with autoimmune features show better survival and less exacerbations compared to idiopathic pulmonary fibrosis. BMC Pulm Med 2019;19:120.

44 Ito $\mathrm{Y}$, Arita M, Kumagai S, et al. Serological and morphological prognostic factors in patients with interstitial pneumonia with autoimmune features. BMC Pulm Med 2017;17:111.

45 Mejía M, Herrera-Bringas D, Pérez-Román DI, et al. Interstitial lung disease and myositis-specific and associated autoantibodies: clinica manifestations, survival and the performance of the new ATS/ERS criteria for interstitial pneumonia with autoimmune features (IPAF). Respir Med 2017;123:79-86.

46 Kelly BT, Moua T. Overlap of interstitial pneumonia with autoimmune features with undifferentiated connective tissue disease and contribution of UIP to mortality. Respirology 2018;23:600-5.

47 Yoshimura K, Kono M, Enomoto Y, et al. Distinctive characteristics and prognostic significance of interstitial pneumonia with autoimmune features in patients with chronic fibrosing interstitial pneumonia. Respir Med 2018;137:167-75

$48 \mathrm{Kim} \mathrm{HC}$, Lee JH, Chae EJ, et al. Long-Term clinical course and outcome of interstitial pneumonia with autoimmune features. Respirology 2019;176.

49 Ley B, Collard HR, King TE. Clinical course and prediction of survival in idiopathic pulmonary fibrosis. Am J Respir Crit Care Med 2011;183:431-40.

50 Song JW, Do KH, Kim MY, et al. Pathologic and radiologic differences between idiopathic and collagen vascular disease-related usual interstitial pneumonia. Chest 2009;136:23-30.

51 Kim EJ, Elicker BM, Maldonado F, et al. Usual interstitial pneumonia in rheumatoid arthritis-associated interstitial lung disease. Eur Respir J 2010;35:1322-8.

52 Bahmer T, Romagnoli M, Girelli F, et al. The use of auto-antibody testing in the evaluation of interstitial lung disease (ILD) - a practical approach for the pulmonologist. Respir Med 2016;113:80-92.

53 Tripepi G, Jager KJ, Dekker FW, et al. Selection bias and information bias in clinical research. Nephron Clin Pract 2010;115:c94-9.

54 King TE, Tooze JA, Schwarz MI, et al. Predicting survival in idiopathic pulmonary fibrosis: scoring system and survival model. Am J Respir Crit Care Med 2001;164:1171-81.

55 Kamiya $\mathrm{H}$, Panlaqui OM, Izumi S, et al. Systematic review and metaanalysis of prognostic factors for idiopathic inflammatory myopathyassociated interstitial lung disease. BMJ Open 2018;8:e023998.

56 Cottin V, Nunes H, Mouthon L, et al. Combined pulmonary fibrosis and emphysema syndrome in connective tissue disease. Arthritis Rheum 2011;63:295-304.

57 Nakamura Y, Chida K, Suda T, et al. Nonspecific interstitial pneumonia in collagen vascular diseases: comparison of the clinical characteristics and prognostic significance with usual interstitial pneumonia. Sarcoidosis Vasc Diffuse Lung Dis 2003;20:235-41. 